\title{
Variations in the strength of conditioned taste aversion in rats as a function of time of inducement
}

\author{
FRANK ETSCORN \\ George Peabody College for Teachers, Nashville, Tennessee 37203 \\ and \\ RICHARD L. MILLER \\ Western Kentucky University, Bowling Green, Kentucky 42101
}

\begin{abstract}
In an experiment to determine the optimal time of day for the establishment of taste-aversion learning, 24 male albino rats were divided into four equal groups. Following 14 days of ad-lib water and food, Group 1 animals were water deprived beginning at 4 a.m. on Day 15. Group 2 was also introduced to water deprivation on Day 15 beginning at 10 a.m.; likewise, Group 3 began at 4 p.m. and Group 4 started at 10 p.m. After $24 \mathrm{~h}$ of deprivation, the taste cues (1.5 grains of saccharin in $600 \mathrm{cc}$ of tap water) were made available to each group at 4 a.m., 10 a.m., 4 p.m., or 10 p.m., respectively. After allowing the animals to drink the taste cue for $1 \mathrm{~h}$, the drinking tubes were removed, and, subsequent to a 30-min interval, each animal was injected with cyclophosphamide, an illness-inducing drug. The subjects were then given 4 days to recover from the ensuing illness with water available ad lib. Upon recovery, the animals in each group were again water deprived for $24 \mathrm{~h}$ using the same times as on Day 15. The next day, all groups were tested for aversions at 4 a.m., 10 a.m., 4 p.m., or 10 p.m., respectively, by giving each animal in each group access for $1 \mathrm{~h}$ to two bottles: one filled with tap water and the other filled with the taste cue. Results indicated that aversions were strongest for the 4 p.m. animals and weakest for the 10 p.m. group. The 4 a.m. and 10 a.m. animals fell between the other two groups in terms of aversion strength.
\end{abstract}

The taste-aversion paradigm can be summarized as follows: If a rat is made ill after having sampled a distinctive tasting solution, the animal will avoid drinking the same liquid if it is subsequently made available (Garcia, Kimeldorf, \& Koelling, 1955). Further, those studies utilizing this paradigm frequently report that training and testing are conducted while the subjects are in the daylight portion of the light-dark cycle (e.g., Ader, 1973; Barker, 1974; Brackbill \& Brookshire, 1971; Elkins, 1974; Green \& Churchill, 1970; Rozin, 1969). According to Young (1961), the rat drinks very little between 6 a.m. and noon; however, during late afternoon and night, the rate of drinking increases, reaching a maximum around midnight. The rat's daylight period is characteristically associated with both a reduction in general activity and in feeding behaviors. Other cyclic fluctuations in behavioral and physiological indices are well documented (Altman, 1967; Brown, 1972).

Recent research (Davis, Navaratnam, \& Redfern, 1973) has indicated that Sprague-Dawley rats show a 24-h rhythm in passive avoidance behavior. Specifically, the maximum avoidance responding was shown to occur in the middle of the light cycle with the minimum of responses occurring during the middle of the dark phase. No reported research has attempted to determine the

Reprints of the article may be obtained from Frank Etscom, Box 512, Psy chobiology, George Peabody College for Teachers, Nash ville, Tennessee 37203 . This research was supported in part by NICHD Grant 00973. existence of cyclic fluctuations in the rat's ability to associate novel tastes with a delayed gastrointestinal malaise. It was therefore hypothesized that taste aversion systematically induced at 6 -h intervals in a $24-\mathrm{h}$ period would vary as a function of the rat's normal feeding/activity period. In effect, it was felt that the rat being a nocturnal feeder would attend to gustatory related cues more so during the dark phase of its day-night cycle than it would in its light portion.

\section{METHOD}

Subjects were 24 male albino rats $(100-105 \mathrm{~g})$ obtained from Sprague-Dawley, Madison, Wisconsin. On their arrival (Day 1), each subject was individually housed in a suspended wire mesh cage and maintained in a $25^{\circ} \mathrm{C}$ lab with a 7 a.m. on $/ 7$ p.m. off fluorescent light cycle. Throughout the entire study, the subjects were fed Purina Lab Chow ad lib. During adaptation (Days 1-14), water was available in one of two 50-cc glass drinking tubes fitted to the fronts of each cage with metal " $C$ " clips (the stainless steel spouts on the tubes were, when attached, approximately $12 \mathrm{~mm}$ apart). To determine the amounts of fluid consumed during adaptation and all ensuing tap water presentations, the drinking tubes were removed as silently as possible at 9:30 a.m. daily, weighed $(.001 \mathrm{~g})$, refilled, weighed again, and then returned to their assigned cages. For all liquid presentations, each pair of tubes were both inserted and removed using a timed, 5-sec interval. During adaptation, no animal was observed to consume all of its allotted water ration prior to the time of daily replenishment. For all subjects, the side with the full tube was counterbalanced across days in order to eliminate any initial preference for drinking from any particular side of the cage. On Day 15, each subject was assigned to one of four $(\mathrm{N}=6)$ groups and then introduced to a $24-\mathrm{h}$ water deprivation 
schedule using the following procedure: The two tubes (one full and one empty) for each subject in Group 1 were removed at 4 a.m. (Day 15), Group 2 subjects were likewise water deprived beginning at $10 \mathrm{a} . \mathrm{m}$. on the same day, Group 3 at 4 p.m., and Group 4 at 10 p.m. At 4 a.m. on Day 16 (treatment day), Group 1 subjects were allowed to drink for $1 \mathrm{~h}$ from two tubes containing the conditioned stimulus (CS). The CS for all groups was a solution comprised of 1.5 grains of saccharin dissolved in $600 \mathrm{cc}$ of tap water. After removal of the CS, each subject was weighed (mean weight per group was 196, 202, 196, and $203 \mathrm{~g}$, respectively) in order to calculate doses of the unconditioned stimulus (US). The US for all groups was cyclophosphamide injected at an intensity of $66 \mathrm{mg} / \mathrm{kg}$ of subject weight. Thirty minutes following removal of the CS, the animals were injected intraperitoneally with the US and returned to their home cages with tap water available ad lib in both drinking tubes. The same method of CS-US presentation was used with Group 2 beginning at 10 a.m., Group 3 at 4 p.m., and Group 4 at 10 p.m. Following one water baseline day (Day 17) with tap water in both tubes, all animals were given 4 days (18-21) with water in one of two tubes as during adaptation. For all subjects, the tubes containing water were positioned on the cages according to a counterbalanced sequence across the 4 days. All groups were again water deprived on Day 22 beginning at the same time as on Day 15. On Day 23, all subjects were tested for aversions by giving them access for $1 \mathrm{~h}$ to two tubes: one filled with the CS and the other filled with tap water. Drinking tubes were introduced at 4 a.m., 10 a.m., 4 p.m., or 10 p.m., respectively, for each of the four groups. The side with the CS was randomized across groups for the two-bottle preference test (Dragoin, McCleary, \& McCleary, 1971).

For the groups treated and tested at 4 a.m. and 10 p.m., a very subdued indirect light source was made available during insertion and removal of the drinking tubes. The source was separated from the experimental animals by two 60 -cage animal racks and, moreover, the experimental animals had their sheet metal cages with wire mesh fronts and bottoms facing toward the darkened end of the lab.

\section{RESULTS}

On the test day (Day 23), a saccharin preference score was computed for each subject (saccharin water/total fluid consumed $\times 100$ ). Using this formula, a score of 50 would indicate an equal preference for plain water and saccharin; likewise, a score of 25 would demonstrate a preference for tap water. The means of these preference scores for the 4 a.m., 10 a.m., 4 p.m., and 10 p.m. groups were $28,39,20$, and 46 , respectively. A one-way analysis of variance yielded significant differences among groups $(\mathrm{F}=14.48, \mathrm{df}=3 / 20, \mathrm{p}<.01)$ while a Scheffé test for combinations indicated a significant difference between the 4 p.m. group and 10 p.m. group $(\mathrm{p}<.05)$. The total amounts of fluid consumed for each subject did not vary between groups on test day $(F<1)$, nor was there a difference in consumption across groups on the last adaptation day $(\mathrm{F}<1)$, treatment day $(\mathrm{F}<1)$, or any of the 4 days following treatment (Days 18-21 with $\mathrm{F}<1$ in each case).

\section{DISCUSSION}

From the results, it appears that the strength (as measured by saccharin preference scores) of conditioned taste aversion varies somewhat as a function of the time of day in which the aversion is established. While it was hypothesized that the rat would show the strongest saccharin avoidance when the aversions were established and tested in the dark cycle, the present data do not support this position. The strongest aversions were shown by the 4 p.m. group (saccharin preference score of 20) while the weakest aversions were evidenced by the 10 p.m. animals (46).

These findings cannot be attributed to differences in initial saccharin preferences as the mean amounts of saccharin water consumed by each group on treatment day were very consistent $(19.6,19.2,18.1$, and $18.7 \mathrm{~g}$, respectively, with $F<1)$. As Levitsky $(1974)$ has shown that diurnal variations in both meal size and meal frequency occur during ad-lib feeding conditions in rats, the possibility existed that different-sized stomach loads could interact with the nausea-inducing agent and produce varying degrees of illness. It is, however, unlikely that the difference in aversion strength between Groups 3 and 4 could be due to differential stomach loads as it has been shown that water deprived rats abstain from eating dry lab chow until their water requirements have been at least partially satisfied (Revusky \& Garcia, 1970). In the present study, we similarly observed feeding during CS presentation and during the 30-min interstimulus interval with cessation of feeding following the cyclophosphamide injections. As there was no significant difference in liquid consumption across groups on treatment day, it is hypothesized that food consumption would be somewhat commensurate. In effect, feeding duration was equivalent for each group with the limiting factor being the onset of illness. The possibility does exist, however, that the observed differences in aversion strength could be due to circadian rhythms in drug susceptibility (Reinberg \& Halberg, 1971). Further, an interesting but statistically untestable trend was observed in that the two strongest aversions (saccharin preference score of 28 for the 4 a.m. animals and 20 for the 4 p.m. group) occurred $9 h$ after a change in lab illumination (or nearest the end of the current cycle). On the other hand, the two weakest aversions occurred $3 \mathrm{~h}$ after a change in illumination (39 for the $10 \mathrm{am}$. animals and 46 for the 10 p.m. animals) or in this case, nearest the beginning of the current cycle.

Finally, as the present study did not include treatment groups in the middle of each light and dark phase, a comparison with the Davis et al. (1973) data is unjustified. The present study does show, however, that the maximum (strongest) aversion occurred during the light phase with the minimum (weakest) aversion occurring during the dark phase (Davis et al. likewise found maximum avoidance responding in the light and a minimum in the dark phase).

\section{REFERENCES}

Ader, R. "Strain" differences in illnessinduced taste aversion. The Bulletin of the Psychonomic Society, 1973, 1, 253-254. 
Altman, J. Organic foundations of animal behavior. New York: Holt, Rinehart, and Winston, 1967.

Barker, L. M., \& Smith, J. C. A comparison of taste aversions induced by radiation and lithium chloride in CS-US and US-CS paradigms. Journal of Comparative and Physiological Psy chology, 1974, 87, 644-654.

Brackbill, R. M., \& Brookshire, K. H. Conditioned taste aversions as a function of the number of CS-US pairs. Psychonomic Science, 1971, 22, 25-26.

Brown, F. A. The "clocks" timing biological rhythms. American Scientist, 1972, 60, 756-766

Davis, J. A., Navaratnam, V., \& Redfern, P. H. A 24-hour rhythm in passive-avoidance behaviour in rats. Psychopharm acologia, 1973, 32, 211-214.

Dragoin, W. B., McCleary, G. L., \& McCleary, P. A comparison of two methods of measuring conditioned taste aversions. Behavioral Research Methods \& Instrumentation, 1971, 3, 309-310.

Elkins, R. L. Bait-shyness acquisition and resistance to extinction as functions of US exposure prior to conditioning. Physiological Psychology, 1974, 2, 341-343.
Garcia, J., Kimeldorf, D. J.. \& Koelling, R. A. Conditioned aversion to saccharin resulting from exposure to gamma radiation. Science, $1955,122,157-158$.

Green, K. F.. \& Cnurcnul, r. A. An errect of flavors on strength of conditioned aversions. Psychonomic Science, 1970, 21, 19-20.

Levitsky, D. A. Feeding conditions and intermeal relationships. Phy siology \& Behavior, 1974, 12, 779-787.

Reinberg, A., \& Halberg. Circadian chronopharmacology. Annual Review of Pharmacology, 1971, 11, 455-492.

Revusky, S. H., \& Garcia, J. Learned associations over long delays. In G. H. Bower (Ed.), The psychology of learning and motivation. New York: Academic Press, 1970.

Rozin, P. Central or peripheral mediation of learning with long CS-US intervals in the feeding system. Journal of Comparative and Physiological Psychology, 1969, 67, 421-429.

Young, P. T. Motivation and emotion. New York: Wiley, 1961.

(Received for publication February 10, 1975; revision accepted March 18, 1975.) 